\title{
Eficiência de Redes Neurais Artificiais na Classificação de Uso e do Solo da Bacia Hidrográfica do Rio Japaratuba - SE
}

\author{
Glauber Vinícius Pinto de Barros ${ }^{1}$ (D), Heliofábio Barros Gomes ${ }^{2}$ (D), Felipe Souza dos Santos ${ }^{1}$ (D), \\ Marcus Aurélio Soares Cruz ${ }^{4}$ (D), Paulo Sergio de Rezende Nascimento ${ }^{3}$ (D), \\ Rafaela Lisboa Costa $^{2}$ (D), Rodrigo Lins da Rocha Júnior ${ }^{1}$ (D), Fabrício Daniel dos Santos Silva ${ }^{2}$ (iD \\ ${ }^{1}$ Programa de Pós-Graduação em Meteorologia, Instituto de Ciências Atmosféricas, \\ Universidade Federal de Alagoas, Maceió, AL, Brasil. \\ ${ }^{2}$ Instituto de Ciências Atmosféricas, Universidade Federal de Alagoas, Maceió, AL, Brasil. \\ ${ }^{3}$ Departamento de Engenharia Ambiental, Universidade Federal de Sergipe, São Cristóvão, SE, \\ Brasil. \\ ${ }^{4}$ Embrapa Tabuleiros Costeiros, Aracaju, SE, Brasil.
}

Recebido em: 29 de Junho de 2020 - Aceito em: 1 de Setembro de 2020

\begin{abstract}
Resumo
O objetivo deste trabalho foi avaliar a eficiência do uso de Redes Neurais Artificiais (RNA) para a classificação de uso do solo da Bacia Hidrográfica do Rio Japaratuba - SE, a partir de uma imagem de sensoriamento remoto. Uma classificação pelo método Máxima Verossimilhança foi realizada para ser comparada com as classificações geradas por RNA, uma vez que o primeiro método já é consolidado na literatura. Para avaliar a eficiência das classificações foram analisados o Índice Kappa, Exatidão Global e Raiz do Erro Médio Quadrático (REMQ). A classificação por Máxima Verossimilhança obteve Índice Kappa de 0,95 e Exatidão Global de 96,43\%. A RNA cuja arquitetura se mostrou mais eficiente obteve Índice Kappa de 0,93, Exatidão Global de 94,14\% e REMQ oscilando entre 0,35 e 0,45 durante suas 10000 iterações, sendo o valor estipulado como ótimo igual a 0,10. As RNA se mostraram eficientes na classificação de uso de solo a partir de imagens de sensoriamento remoto, tendo em vista que os resultados dos parâmetros de acurácia apresentaram valores que indicam uma concordância quase perfeita na classificação realizada por seis das oito arquiteturas de RNA testadas. Dessa forma os produtos gerados podem ser utilizados como ferramenta técnico-gerencial para a gestão ambiental da área de estudo.
\end{abstract}

Palavras-chave: sensoriamento remoto, processamento digital de imagem, métodos não-paramétricos.

\section{Efficiency of Artificial Neural Networks in the Use and Soil Classification of the Japaratuba River Hydrographic Basin - SE}

\begin{abstract}
The objective of this work was to evaluate the efficiency of the use of Artificial Neural Networks (ANN) for the classification of land use of the Japaratuba River Basin - SE, from a remote sensing image. A classification by the Maximum Likelihood method was performed to be compared with the classifications generated by ANN, since the first method is already consolidated in the literature. To assess the classifications efficiency, the Kappa Index, Global Accuracy and Root Mean Square Error (RMSE) were analyzed. The Maximum Likelihood classification obtained Kappa Index of 0.95 and Global Accuracy of $96.43 \%$. The ANN architecture more efficient obtained a Kappa Index of 0.93, Global Accuracy of $94.14 \%$ and RMSE oscillating between 0.35 and 0.45 during its 10,000 iterations, while the value stipulated as excellent was 0.10 . The ANN proved to be efficient in the classification of land use from remote sensing images, since the results of the accuracy parameters showed values that indicate an almost perfect agreement in the classification performed by six of the eight ANN's architectures tested. Thus the generated products can be used as a technical-managerial tool for the environmental management of the study area.
\end{abstract}

Keywords: remote sensing, digital image processing, non-parametric methods.

Autor de correspondência: Glauber Vinícius Pinto de Barros, glauber.barros@hotmail.com. 


\section{Introdução}

$\mathrm{O}$ rápido progresso na tecnologia de sensoriamento remoto e a redução dos custos de aquisição proporcionaram um grande volume de imagens da Terra prontamente disponíveis hoje em dia. Elas são tomadas de satélites ou aviões, com várias resoluções espaciais, espectrais, temporais e radiométricas. Essa grande variedade de características das imagens multiespectrais de sensoriamento remoto permite com que os softwares atuais de Processamento Digital de Imagens (PDI) forneçam produtos com resultados confiáveis e maximizando o tempo operacional.

De acordo com Jensen (2009), a classificação de imagem pode ser definida sumariamente como um processo que consiste em agrupar pixels, a partir de suas características, em classes pré-estabelecidas ou não pelo usuário. No contexto do processamento digital de imagens, esses métodos são empregados com o objetivo de reconhecer classes/categorias de pixels na imagem, sendo dessa forma denominado genericamente por classificação de imagens.

De maneira geral, os classificadores podem ser divididos em paramétricos e não paramétricos. Dentre os métodos de abordagem da estatística paramétrica de classificação de imagens, a Máxima Verossimilhança é um dos mais usados. Segundo Meneses e Almeida (2012), o método da Máxima Verossimilhança considera a ponderação das distâncias entre as médias dos valores dos pixels das classes, utilizando parâmetros estatísticos. Assume-se que todas as bandas têm distribuição normal e calcula a probabilidade de um dado pixel pertencer a uma classe específica. É um classificador eficiente porque as classes de treinamento são utilizadas para estimar a forma da distribuição dos pixels contidos em cada classe no espaço de inúmeras bandas, como também a localização do centro de cada classe.

Para Andrade et al. (2014) o desempenho e a exatidão dos classificadores que usam a estratégia paramétrica, como a Máxima Verossimilhança, estão diretamente ligados à distribuição normal dos dados. O problema reside nas imagens que apresentam comportamento mais heterogêneo, assim como nas feições anômalas encontradas em imagens mais homogêneas.

Os classificadores contextuais ou não paramétricos diferenciam-se dos primeiros por não assumirem hipóteses a respeito da natureza estatística dos dados, na medida em que podem ser empregados com distribuições que não obedeçam aos parâmetros da curva normal. Dentre os classificadores não paramétricos estão as Redes Neurais Artificias (RNA). Segundo Castelluccio et al. (2015) as RNA se inspiram em modelos da biologia cerebral, e tentam reproduzir algumas de suas funções usando simples unidades de processamento, porém fortemente interconectadas, os neurônios. Uma arquitetura típica de rede neural compreende várias camadas de neurônios alimentando um ao outro, quanto mais camadas, mais profunda é dita a rede. Recentemente, as redes neurais têm sido aplicadas em atividades de sensoriamento remoto, como em Midhun et al. (2014); Chen et al. (2015) e Penatti et al. (2015).

Nesse contexto, o objetivo desse trabalho foi avaliar o comportamento de RNA em comparação com os resultados obtidos por Máxima Verossimilhança para a classificação de uso do solo da Bacia Hidrografia do Rio Japaratuba - SE (BHRJ). Para atingir esses objetivos foram determinados os seguintes objetivos específicos: (i) empregar dois tipos de classificadores supervisionados (pixel a pixel) a uma imagem sensoriada da BHRJ; (ii) comparar os produtos gerados por meio da estatística Kappa e Exatidão Global (iii) testar diferentes arquiteturas de redes neurais e compará-las através da Raiz do Erro Médio Quadrático.

A relevância e a justificativa da realização desse trabalho são atribuídas a: (i) contribuir para as pesquisas afim de entender e definir as melhores maneiras de aplicação das RNA em sensoriamento remoto; (ii) atualizar o mapa de uso do solo, uma vez que o oficial mais recente é de
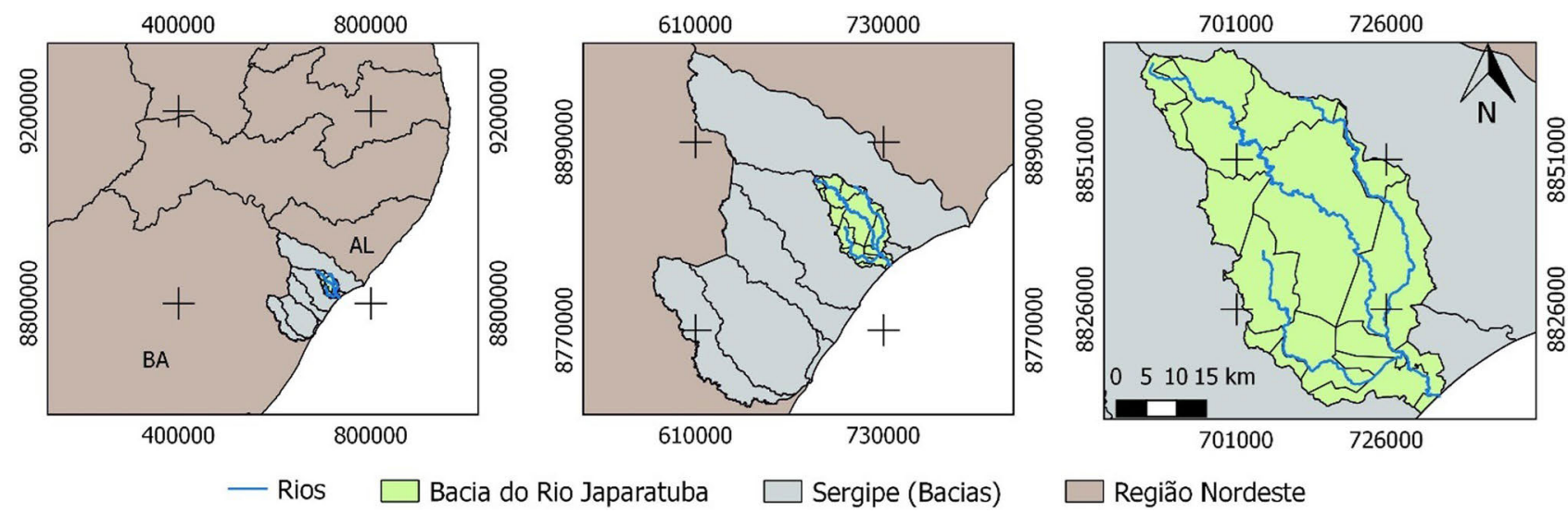

Figura 1 - Mapa de localização da Bacia Hidrográfica do Rio Japaratuba. 
2010, realizado pela Secretaria Estadual de Meio Ambiente e Recursos Hídricos (SEMARH).

\section{Materiais e Métodos}

A área de estudo deste trabalho, a Bacia Hidrográfica do Rio Japaratuba, está totalmente inserida no Estado de Sergipe, como consta na Fig. 1. Possui uma área de $1685 \mathrm{~km}^{2}$, perímetro de $247,30 \mathrm{~km}$ e o rio principal, que dá nome à bacia, tem extensão de $135 \mathrm{~km}$.

De acordo com Aragão et al. (2012), a Bacia Hidrográfica do Rio Japaratuba possui três regiões climáticas com diferentes regimes de precipitação: litoral úmido (1000-1400 mm), agreste (700-900 mm) e semiárido (400$700 \mathrm{~mm}$ ) e período chuvoso entre janeiro e maio como mostra a Fig. 2a. A temperatura média anual é de $25^{\circ} \mathrm{C}$ e a umidade relativa do ar é de aproximadamente 74\%. Da área total da bacia, 9,63\% pertencem à região semiárida, $30,18 \%$ a porção litoral úmida e $60,17 \%$ estão localizadas no agreste.

O Atlas Digital sobre recursos hídricos de Sergipe da Secretaria de Estado do Meio Ambiente e Recursos Hídricos (SEMARH, 2016), em seus dados vetoriais de classes de solo, consta que para a Bacia Hidrográfica do Rio Japaratuba, a predominância a montante do Luvissolo $\left(570,4 \mathrm{~km}^{2}\right)$ na porção média Argilossolo $\left(650,7 \mathrm{~km}^{2}\right)$ e a jusante Vertissolo $\left(127,7 \mathrm{~km}^{2}\right)$ e Espedossolo $\left(66,6 \mathrm{~km}^{2}\right)$, como pode ser visto na Fig. 2b. Os mapas apresentados nas figuras deste trabalho foram elaborados através do software QGIS 2.18, os dados se encontram na Projeção Universal Transversa de Mercator no Datum Horizontal SIRGAS-2000 zona 24-S.

A imagem multiespectral utilizada para o desenvolvimento deste trabalho foi imageada pelo sensor OLI do satélite Landsat-8, sendo referente à órbita e ponto $215 / 67$, passagem de 05 de dezembro de 2017 as $12: 35 \mathrm{~h}$, com cobertura de nuvens de apenas $1,18 \%$.

\subsection{Processamento digital}

\subsubsection{Preparação das imagens}

O Processamento digital dos dados foi realizado no software ENVI 5.1. O primeiro procedimento realizado foi o recorte da imagem, definido por um retângulo envolvente da Bacia Hidrográfica do Rio Japaratuba. O próximo procedimento foi a escolha das bandas espectrais para a classificação automática, a partir da realização de uma Análise de Componentes Principais (ACP) das bandas 1 a 7 da imagem multiespectral. Segundo Ingebritsen e Lyon (1985), a ACP é uma técnica estatística que transforma um conjunto de dados multivariados, formado por variáveis correlacionadas, em um conjunto de dados formados por variáveis que são combinações lineares não correlacionadas das variáveis originais.
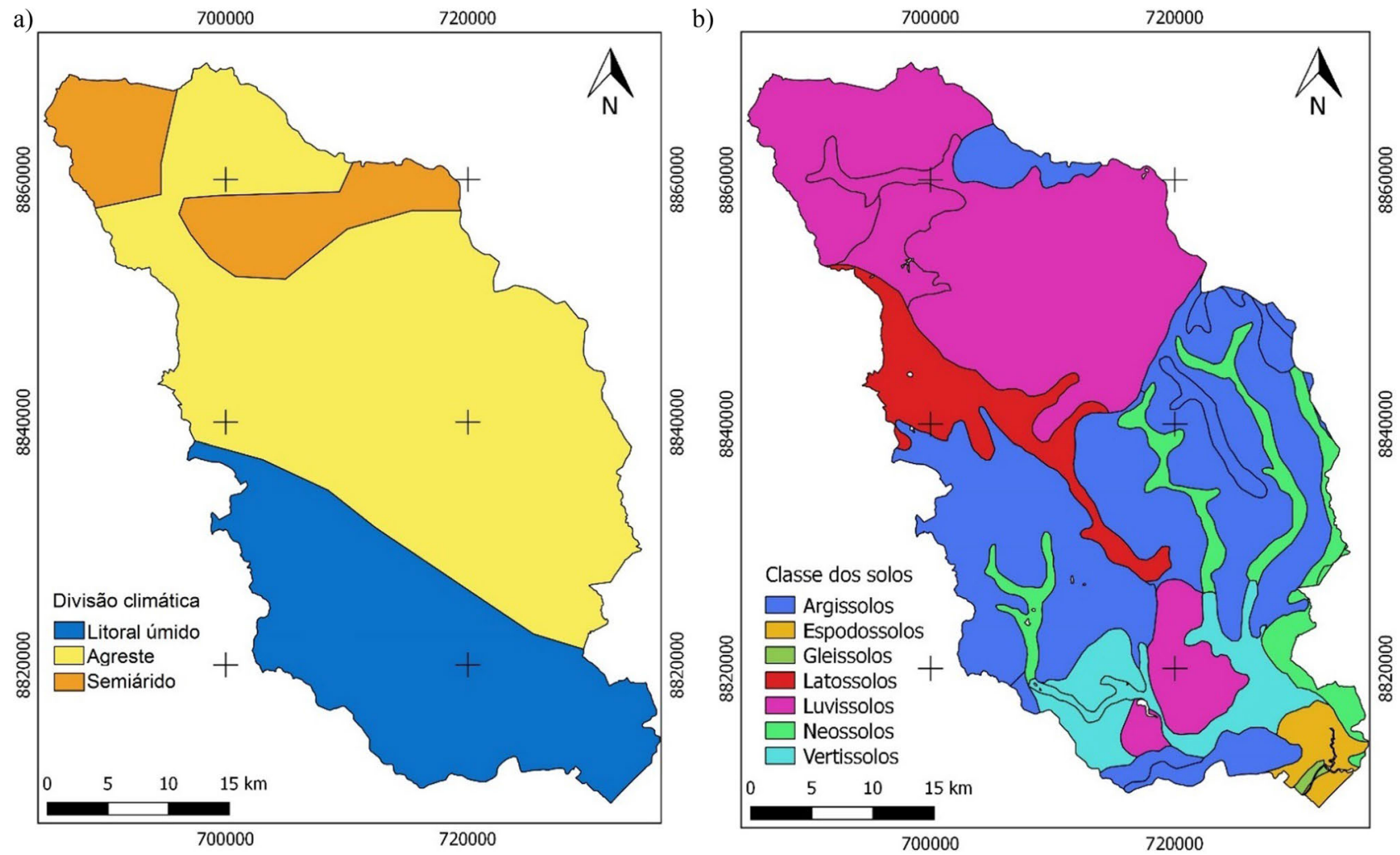

Figura 2 - Divisão climática (a) e Classes de solos presentes (b) da Bacia hidrográfica do Rio Japaratuba. Fonte: Adaptado do Atlas Digital da SEMARH, 2016. 
As bandas de uma imagem multiespectral são altamente correlacionadas, visualmente e numericamente (valores dos pixels), o que pode causar uma ineficiência na análise das bandas espectrais. Dessa forma ao usar-se da ACP em imagens multiespectrais é possível criar novas imagens em que as bandas individuais são independentes, ou seja, não correlacionadas. As novas imagens, Componentes Principais (CP), são resultantes da transformação derivada da matriz de covariância dos valores originais. Os componentes principais são gerados em número igual aos das bandas de entrada, ordenados em ordem decrescente em função da variação do nível de cinza em porcentagem. Este procedimento gera uma tabela com os autovalores e a porcentagem de informação de cada CP criados, em função da variação do nível de cinza.

Após escolhidas as três bandas espectrais de acordo com o resultado da ACP, foi realizada uma fusão das bandas selecionadas com a banda Pancromática (banda 8), afim de aumentar a resolução espacial das imagens, de $30 \mathrm{~m}$ para $15 \mathrm{~m}$. A fusão das imagens foi realizada a partir de uma transformação do espaço de cores, Vermelho (R) Verde (G) - Azul (B), ou seja, RGB, para o espaço de cores, Intensidade (I) - Matiz (H) - Saturação (S), IHS. Em seguida, uma transformação IHS-RGB, onde os componentes $\mathrm{H}$ e $\mathrm{S}$ que guardam a informação espectral das cores são preservados e o componente I é descartado e substituído pela imagem pancromática de alta resolução espacial. Por fim foi gerada a composição colorida RGB. A técnica utilizada para o realce da imagem foi o Contraste Linear, de modo a tentar melhorar a qualidade da imagem de acordo com os critérios subjetivos da visão humana para facilitar a aquisição das amostras de treinamento.

\subsubsection{Definição das amostras de treinamento}

Este procedimento foi realizado no software ENVI 5.1, a partir da delimitação de pixels representativos das amostras de cada classe. Foram selecionados 200 pixels representativos de cada uma das classes de uso e ocupação do solo. Totalizando 1400 pixels, uma vez que foram definidas 7 classes, sendo essas: área urbana (AU); corpos d'água (CDA); cultivos agrícolas (CA); florestas (FLO); manguezais (MAN); pastagens (PAS) e solo exposto (SE). Para a escolha das amostras foram analisados os elementos fotointerpretativos, como por exemplo, as características espectrais, padrões e demais feições dos alvos reconhecidos. No entanto, na área estudada existem outros tipos de classes, as quais foram associadas nas classes supracitadas. Tal redução em 7 classes se deu devido ao fato de a área de estudo ser heterogênea, apresentando intensa relação entre as classes. Como consequência direta haveria a dificuldade de adquirir amostras puras o que ocasionaria uma elevada confusão espectral no processo de classificação.

\subsection{A execução dos métodos de classificações}

Na classificação por Máxima Verossimilhança, cada pixel é destinado à classe que tem a mais alta probabilidade. Ou seja, dado um pixel numa posição do espaço multiespectral, um conjunto de probabilidades é computado dando as possibilidades relativas do pixel pertencer a cada classe disponível.

Segundo Srivastava et al. (2012), o algoritmo de classificação por Máxima Verossimilhança é baseado no Teorema de Bayes de tomada de decisão, em que as células em cada amostra das classes no espaço multidimensional seguem uma distribuição normal. Assumindo que cada amostra de classe é normal, uma dada classe pode ser caracterizada pelo vetor normal e pela matriz de covariância.

De acordo com Otukei e Blaschke (2010), a probabilidade de um vetor $(X)$, de medidas dos pixels a serem classificados, pertencer a uma das classes c pode ser dada pela Eq. (1):

$$
\begin{aligned}
& D=\ln \left(a_{c}\right)-\left[0,5 \ln \left(\left|\operatorname{cov}_{c}\right|\right)\right] \\
& -\left[0,5\left(X-M_{c}\right) T\left(\operatorname{cov}_{c}-1\right)\left(X-M_{c}\right)\right]
\end{aligned}
$$

em que $(D)$ é a probabilidade de o vetor $(X)$ pertencer a uma dada classe $(c)$. Mc é o vetor das médias para cada classe $(c),(a c)$ é porcentagem da probabilidade de cada pixel em pertencer a uma classe ( $a c$ é conhecido como limiar de aceitação e é previamente definido pelo operador), $\left(\operatorname{cov}_{c}\right)$ é a matriz de covariância de cada classe, e (T) é a matriz transposta.

O Método de Máxima Verossimilhança foi executado com um limiar de aceitação de $95 \%$. Esse limiar estabelece um limite para o processo de decisão de separabilidade dos pixels entre as classes. Abaixo do valor estipulado os pixels não eram considerados como sendo pertencentes à classe em questão.

Segundo Srivastava et al. (2012), o modelo básico de RNA consiste em uma camada de entrada, uma camada oculta e uma camada de saída. Para classificação de imagem, cada neurônio na camada de entrada representa uma das entradas características, como uma banda de imagem de satélite, enquanto cada neurônio na camada de saída corresponde a uma das classes. A Fig. 3 apresenta uma representação simplificada da arquitetura de uma rede neural.

De acordo com Okwuashi et al. (2012), basicamente o sinal de um neurônio $i$ da camada de entrada, de uma célula $(x)$, em um dado tempo $(t)$, recebido por um neurônio $(j)$ da camada intermediária, pode ser expresso de acordo com a Eq. (2):

$$
n e t_{j}(x, t)=\sum_{j} W_{i, j} S_{i}^{\prime}(x, t)
$$




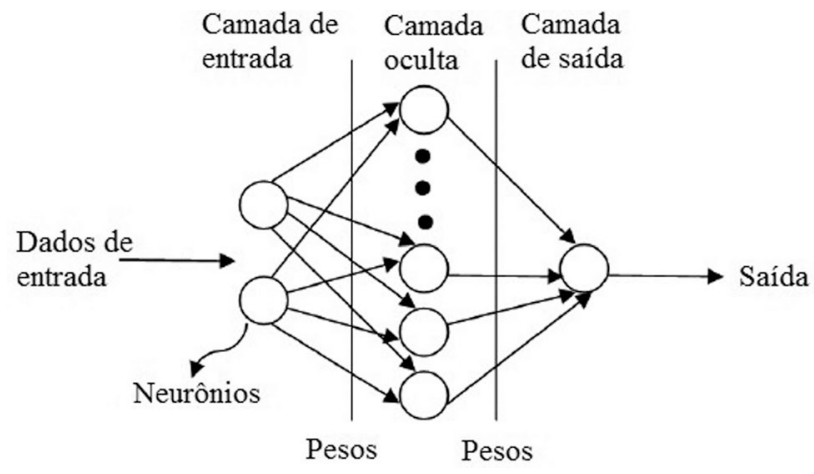

Figura 3 - Exemplo genérico de uma rede neural artificial. Fonte: Adaptado de com Okwuashi et al. (2012).

sendo $\left(S_{i}^{\prime}(x, t)\right)$ os atributos da célula dados pela variável (neurônio) $(i)$ e $\left(W_{i, j}\right)$ é o peso da entrada do neurônio $(i)$ ao neurônio $(j)$.

O modelo de rede neural utilizado nesse trabalho foi o backpropagation. Esse tipo de RNA tem resultados superiores para classificações supervisionadas e é comummente utilizada em sensoriamento remoto devido sua facilidade de aprender os padrões das classes. As redes neurais foram executadas de modo que seus parâmetros foram alterados resultando em oito arquiteturas diferentes, em um processo semelhante ao realizado por Ndehedehe et al. (2013). Foram variados os valores dos parâmetros: Training Threshold Contribution (TTC), que quantifica o peso de contribuição das informações utilizadas pelos neurônios, variando de 0 a 1; Training Rate (TR) que é a taxa de aprendizado da rede, variando de 0 a 1 , uma taxa mais alta irá acelerar o treinamento, mas também aumentará o risco de oscilações ou não-convergência do resultado do treinamento; Training Momentum (TM), cujo efeito atua na mudança de pesos ao longo das sinapses da rede neural, variando de 0 a 1 , uma taxa de momentum mais alta treina com passos maiores do que uma taxa de momentum mais baixa; Training Root Mean Square Exit Criteria (RMSEC), é o critério de parada das iterações a depender da Raiz do Erro Médio Quadrático (Root Mean Square Error - RMSE), se esse o valor do RMSE durante a fase de treinamento atingir um valor abaixo do valor estipulado, o treinamento será encerrado e a classificação será realizada; Number of Hidden Layers (NHL), é o número de camadas ocultas (intermediárias) que a rede neural irá utilizar; Number of Training Iterations (NTI), é o número de iterações que a rede neural irá realizar para o treinamento da rede.

\subsection{Verificação da acurácia}

A acurácia dos dois classificadores automáticos foi avaliada utilizando-se o Índice Kappa e a Exatidão Global, através da análise da Matriz de Confusão. Para os resultados das redes neurais ainda foi utilizado a Raiz do Erro Médio Quadrático (REMQ), do inglês, Root Mean
Squares Error (RMSE). De acordo com Leão et al. (2007), o Índice Kappa $(\mathrm{k})$, mede o grau de concordância da classificação digital com a verdade de campo, nesse caso com as amostras de treinamento. A Exatidão Global é dada pela divisão entre os números de pixels corretamente classificados e o número total de pixels. Segundo Chagas et al. (2009), o Índice Kappa pode ser obtido pela Eq. (3):

$$
k=\frac{n \sum_{i=1}^{c} x_{i i}-\sum_{i=1}^{c} x_{i \oplus} x_{i \oplus i}}{n^{2}-\sum_{i=1}^{c} x_{i \oplus} x_{\oplus i}}
$$

em que, (xii) é o valor na linha (i) e coluna (i); linhas totais $(x i \oplus)$ é a soma de linhas $(i)$ e colunas totais $(x \oplus)$ é a soma das colunas ( $i$ ) da matriz de confusão; $(n)$ é o número total de amostras e (c), o número total de classes. A Tabela 1 apresenta os valores e os níveis de concordância da classificação.

Para as redes neurais o RMSE indica o quanto a rede neural aprendeu dos padrões que lhe foram repassados durante a fase de aprendizado durante cada iteração da rede neural. O RMSE, segundo Wang e Lu (2018), pode ser calculado de acordo com a Eq. (4), onde $\left(y_{i}\right)$ é o iésimo valor no instante; $\left(y_{p}\right)$ o valor previsto e $(N)$ é o número de dados no instante, uma vez que o RMSE no pacote de redes neurais do software utilizado é calculado ao longo de cada iteração realizada pela rede neural.

$$
R M S E=\sqrt{\frac{\sum_{i=1}^{N}\left(y_{i}-y_{p}\right)^{2}}{N}}
$$

\section{Resultados e Discussão}

A Tabela 2 apresenta os resultados obtidos pela ACP. Pode-se constatar que as CP 1, 2 e 3 são responsáveis por conter $99,80 \%$ das informações de variação dos níveis de cinza.

A Fig. 4 apresenta o resultado da composição colorida falsa cor, com a seguinte configuração: CP1 (vermelho), CP2 (azul) e CP3 (verde), realçada pelo contraste Linear.

Para a classificação de uso do solo por Máxima Verossimilhança, os valores encontrados para Exatidão Global e Índice Kappa foram respectivamente 96,43\% e 0,95.

Tabela 1 - Interpretação do índice kappa. Adaptado de Ndehedehe et al. (2013).

\begin{tabular}{ll}
\hline Kappa & Concordância \\
\hline$<0$ & Sem concordância \\
$0,0-0,20$ & Ligeira concordância \\
$0,21-0,40$ & Regular concordância \\
$0,41-0,60$ & Moderada concordância \\
$0,61-0,80$ & Substancial concordância \\
$0,81-1,00$ & Quase perfeita concordância \\
\hline
\end{tabular}


Tabela 2 - Resultado da ACP para as bandas da imagem multiespectral.

\begin{tabular}{lcc}
\hline CP & Autovalor & Porcentagem \\
\hline CP1 & 290758890,08 & 96,21 \\
CP2 & 7000941,69 & 2,32 \\
CP3 & 3833394,27 & 1,27 \\
CP4 & 425270,01 & 0,14 \\
CP5 & 138468,71 & 0,05 \\
CP6 & 36950,58 & 0,01 \\
CP7 & 14669,22 & 0,00 \\
\hline
\end{tabular}

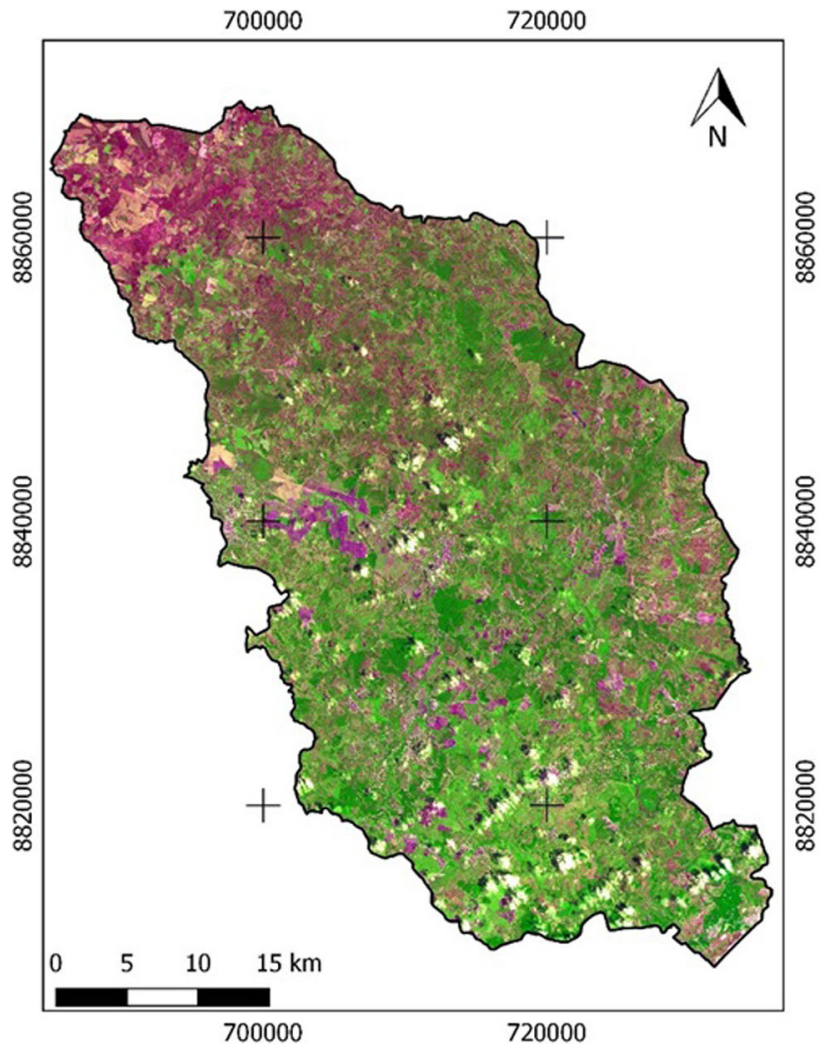

Figura 4 - Composição colorida falsa cor CP1(R), CP2(B) e CP3(G), realçada pelo contraste Linear.

O índice Kappa encontrado indica um nível de concordância quase perfeito entre a classificação e o conjunto de amostras. Pode-se constatar que a todas as classes, com exceção da classe cultivos agrícolas e pastagem resultaram em exatidões do produtor acima de $95 \%$. Nessas duas classes citadas, houve confusão espectral de pixels da classe cultivos agrícolas que foram classificados como pixels pertencentes a classe pastagem. Isso ocorre, pois, as áreas de cultivos agrícolas presentes na área de estudos possuem diferentes valores de níveis de cinza, os quais variam a depender de diferentes fases de cultivo (solo exposto, solo preparado, plantio recente, plantio pronto para colheita). A Tabela 3 apresenta os resultados obtidos para a matriz de confusão da classificação por Máxima Verossimilhança.
A Fig. 5 apresenta o mapa de classificação de uso e ocupação do solo para a área de estudo obtida a partir da classificação por Máxima Verossimilhança. O mapa está georreferenciado no Sistema de Referência Geocêntrico para as Américas (SIRGAS-2000), na projeção Universal Transversa de Mercator, zona 24 sul.

A Tabela 4 apresenta os valores os valores utilizados para os parâmetros que foram variados para as oito diferentes arquiteturas de redes neurais e seus resultados para o Índice Kappa e Exatidão Global (EG).

Pode-se constatar a partir da Tabela 4 que os melhores resultados foram obtidos para as RNA 3, 2 e 8, com valores de Índice Kappa de 0,93, 0,93 e 0,92 respectivamente. As RNA 3 e 2 diferem apenas no número de iterações, de 5000 para 10000 , o que mostra que a variação apenas deste parâmetro em relação aos demais, produz uma melhora na eficiência. $\mathrm{O}$ mesmo pode ser observado nas RNA 6,7 , e 8, onde os outros parâmetros foram mantidos iguais variando-se apenas o número de iterações, percebendo-se um aumento na Exatidão Global e Kappa. Observou-se que um incremento do número de camadas ocultas de 1 para 2 acarretou numa piora expressiva dos resultados, mesmo com o aumento de número de iterações, como mostra os resultados de Índice Kappa. A Fig. 6

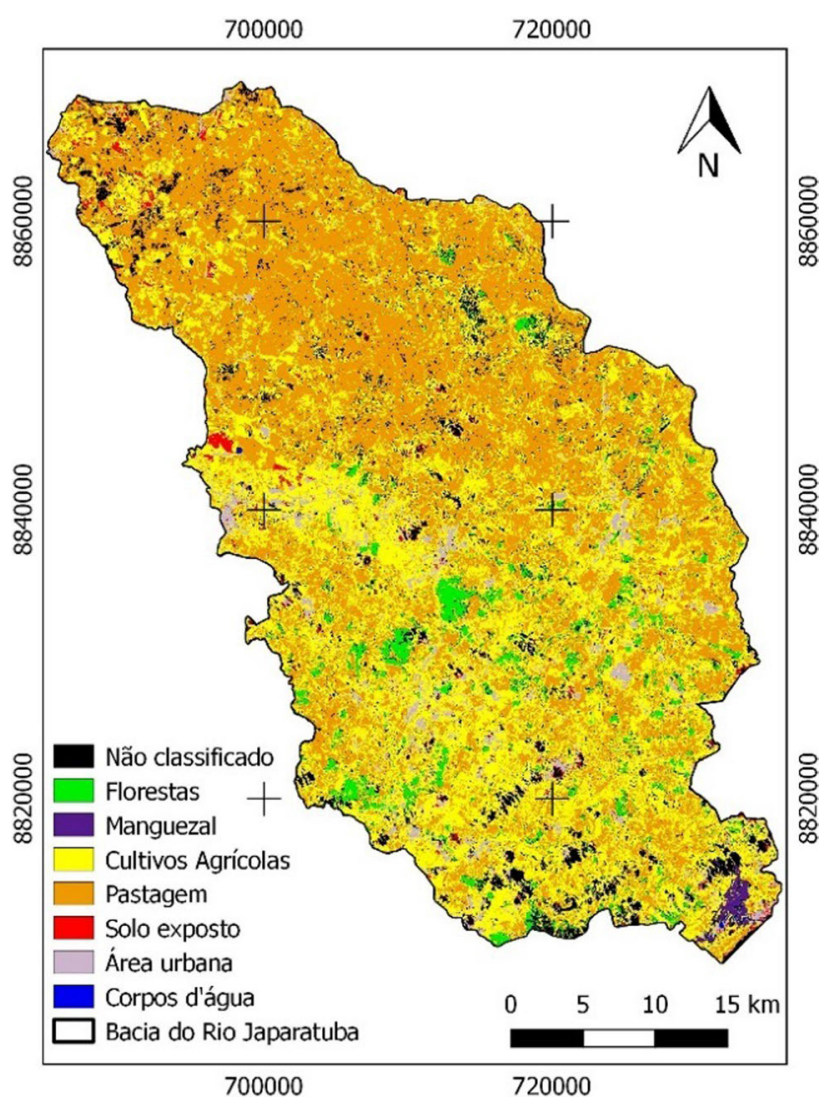

Figura 5 - Mapa de classificação de uso e ocupação do solo obtido por Máxima Verossimilhança. 
Tabela 3 - Matriz de Confusão para a classificação por Máxima Verossimilhança.

\begin{tabular}{|c|c|c|c|c|c|c|c|c|}
\hline Classe & FLO & MAN & $\mathrm{CA}$ & PAS & SE & $\mathrm{AU}$ & $\mathrm{CDA}$ & Total \\
\hline Não classificado & 2 & 10 & 0 & 0 & 0 & 0 & 7 & 19 \\
\hline FLO & 198 & 0 & 0 & 0 & 0 & 0 & 0 & 198 \\
\hline MAN & 0 & 190 & 0 & 0 & 0 & 0 & 0 & 190 \\
\hline $\mathrm{CA}$ & 0 & 0 & 175 & 0 & 1 & 3 & 0 & 179 \\
\hline PAS & 0 & 0 & 25 & 200 & 0 & 0 & 0 & 225 \\
\hline SE & 0 & 0 & 0 & 0 & 197 & 0 & 0 & 197 \\
\hline $\mathrm{AU}$ & 0 & 0 & 0 & 0 & 2 & 197 & 0 & 199 \\
\hline $\mathrm{CDA}$ & 0 & 0 & 0 & 0 & 0 & 0 & 193 & 193 \\
\hline Total & 200 & 200 & 200 & 200 & 200 & 200 & 200 & 1400 \\
\hline Exatidão do produtor (\%) & 99,00 & 95,00 & 87,50 & 100,0 & 98,5 & 98,5 & 96,50 & 96,43 \\
\hline Exatidão do usuário (\%) & 100,0 & 100,0 & 97,77 & 88,89 & 100,0 & 98,99 & 100,0 & \\
\hline
\end{tabular}

Tabela 4 - Parâmetros das redes neurais executadas e suas Exatidões Global e kappa.

\begin{tabular}{lcccccccc}
\hline Parâmetro & RNA & RNA & RNA & RNA & RNA & RNA & RNA & RNA \\
& 1 & 2 & 3 & 4 & 5 & 6 & 7 & 8 \\
\hline TTC & 0,90 & 0,90 & 0,90 & 0,90 & 0,90 & 0,90 & 0,90 & 0,90 \\
TR & 0,20 & 0,20 & 0,20 & 0,20 & 0,20 & 0,90 & 0,90 & 0,90 \\
TM & 0,90 & 0,90 & 0,90 & 0,90 & 0,90 & 0,10 & 0,10 & 0,10 \\
RMSEC & 0,10 & 0,10 & 0,10 & 0,10 & 0,10 & 0,08 & 0,08 & 0,08 \\
NHL & 1,00 & 1,00 & 1,00 & 2,00 & 2,00 & 1,00 & 1,00 & 1,00 \\
NTI & 1000 & 5000 & 10000 & 1000 & 5000 & 1000 & 5000 & 10000 \\
EG (\%) & 90,5 & 93,92 & 94,14 & 59,14 & 47,93 & 88,21 & 92,28 & 93,21 \\
Kappa & 0,88 & 0,93 & 0,93 & 0,52 & 0,39 & 0,86 & 0,91 & 0,92 \\
\hline
\end{tabular}

apresenta o comportamento da Raiz do Erro Médio Quadrático.

Em relação a Raiz do Erro Médio Quadrático (REMQ), nenhuma RNA chegou a ter valores abaixo do estipulado durante as iterações, valores baixos de REMQ significam uma menor distância normalizada entre o vetor de valores estimados e o vetor de valores observados, o que indica que o erro da RNA em classificar a imagem é menor.

Os menores patamares de REMQ foram identificados nas RNA 1, 2 e 3, com os valores oscilando entre 0,35 a 0,45 durante suas iterações, respectivamente 1000,5000 e 10000, tais RNA obtiveram Índices Kappa considerados de quase perfeita concordância. A RNA 8, apesar de ter resultado um Kappa de 0,92, apresentou o REMQ desenvolvido de maneira mais irregular ao longo das 10000 interações realizadas e num patamar acima das outras RNA com kappa semelhante.

Quanto ao RMSEC, foi mais eficiente manter de 0,10 a 0,08 . Ndehedehe et al. (2013) constataram que os valores de RMSEC devem ser mantidos abaixo de 0,10 , enquanto a Taxa de Treinamento e o Momento de Treinamento podem variar entre 0,90 e 0,10 para melhores resultados, com o número de camadas ocultas otimizado em apenas uma. Chegando a alcançar Exatidão Global e kappa de 87,50 e 0,84 para sua arquitetura correspondente a RNA 6 deste trabalho e $86,52 \%$ e 0,82 para sua arquitetura correspondente a arquitetura da RNA 1.

A Fig. 7 apresenta o resultado das classificações de uso do solo para todas as arquiteturas de redes neurais artificiais utilizadas. Trabalhos como os de Srivastava et al. (2012), Szuster et al. (2011), Zang e Chang (2015) e Ndehedeh et al. (2013) corroboram com os resultados encontrados, ao avaliarem o desempenho dos classificadores por Máxima Verossimilhança e o mesmo tipo de rede neural utilizada neste trabalho, a do tipo backpropagation. Srivastava et al. (2012), afirmam que a escolha do número apropriado de camadas ocultas depende da estrutura dos dados, variando de uma a três em seu trabalho de seleção de técnicas de classificação de uso do solo para a detecção de mudanças, tendo o número de camadas ocultas fixado em uma. Apesar de não descreverem detalhadamente em seu trabalho, os valores atribuídos aos demais parâmetros das redes neurais, obtiveram ótimos resultados ao comparar uma classificação por máxima verossimilhança e redes neurais. Para a classificação por máxima verossimilhança chegou aos 82,27\% para Exatidão Global e 0,72 para o Kappa. Já para a rede neural encontrou $84,90 \%$ de Exatidão Global e 0,75 para o Kappa.

Szuster et al. (2011), em seu trabalho de comparação de técnicas de classificação de uso do solo par áreas de zonas costeiras tropicais, comparou os resultados de Exatidão Global e Índice Kappa entre classificações de uso do solo por máxima verossimilhança e redes neurais, utilizando-se de apenas uma camada oculta, fixando os demais parâmetros e reduzindo os valores de Trainning Threshold Contribution de 0,90 a 0,10 , chegaram a resultados de 93,90\% para a Exatidão Global da classificação por máxima verossimilhança e $94,99 \%$ para a rede neural.

Zang e Chang (2015), em seu estudo de classificação de imagens de sensoriamento remoto baseado em redes neurais do tipo backpropagation, ao analisarem imagens 

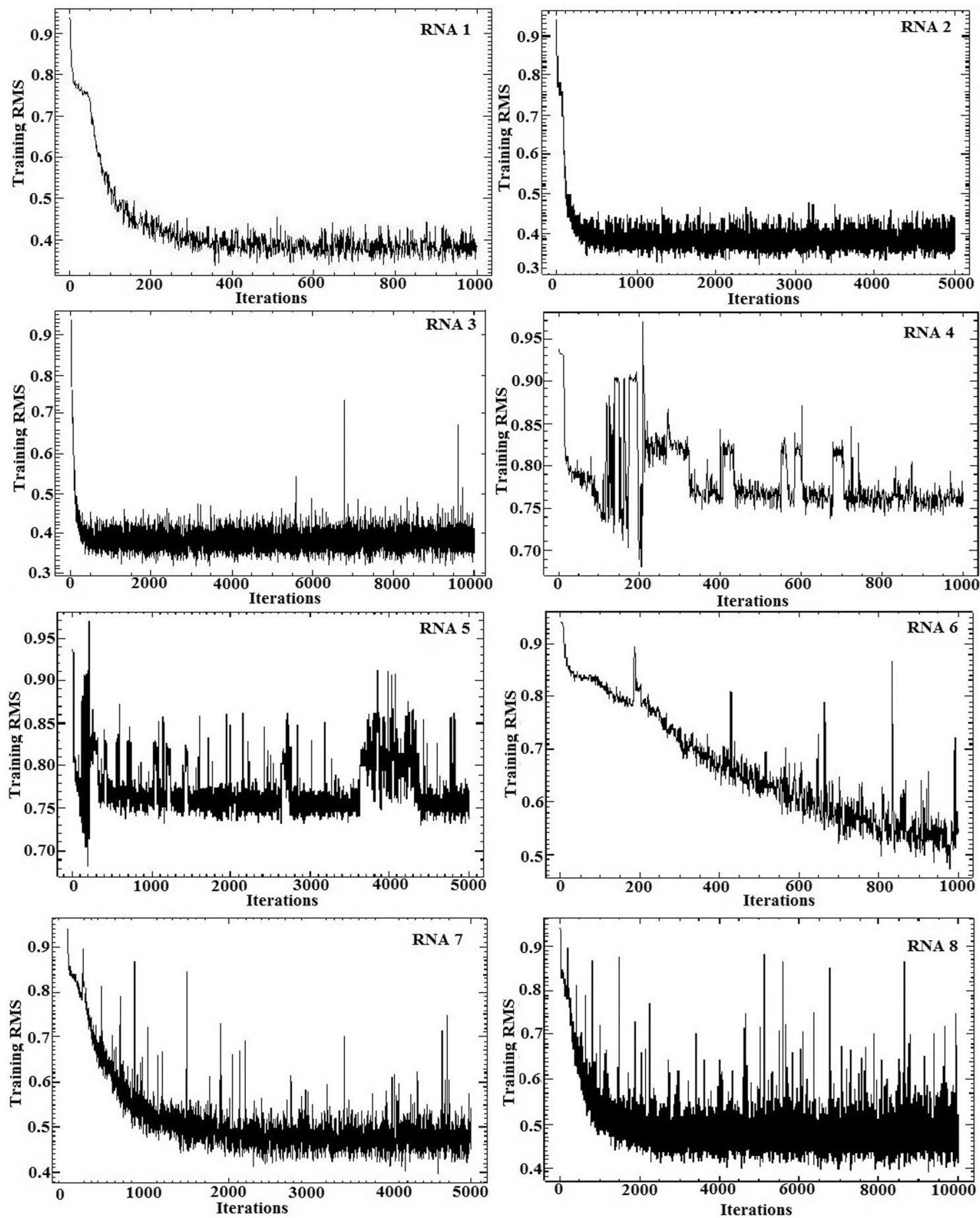

Figura 6 - Comportamento da Raiz do Erro Médio Quadrático no decorrer das iterações de treinamento das RNA.

da cidade de Ningde, na China, obtidas a partir do satélite Landsat-8, realizaram classificações por RNA, Máxima verossimilhança, Paralelepípedo e Distância Mínima. As RNA e a Máxima Verossimilhança se mostraram os dois melhores métodos respectivamente, com Exatidão Geral e Índice Kappa de 95,07\% e 0,93 para o primeiro e 90,76\% e 0,88 para o segundo.
De maneira geral, apenas as classificações obtidas pelas redes neurais 4 e 5 obtiveram resultados destoantes das demais classificações, com concordâncias moderada e regular respectivamente de acordo com o Índice Kappa. Essas duas classificações foram, justamente, as geradas pelas redes cujas arquiteturas continham dois neurônios na camada oculta. Os resultados das classificações das redes 


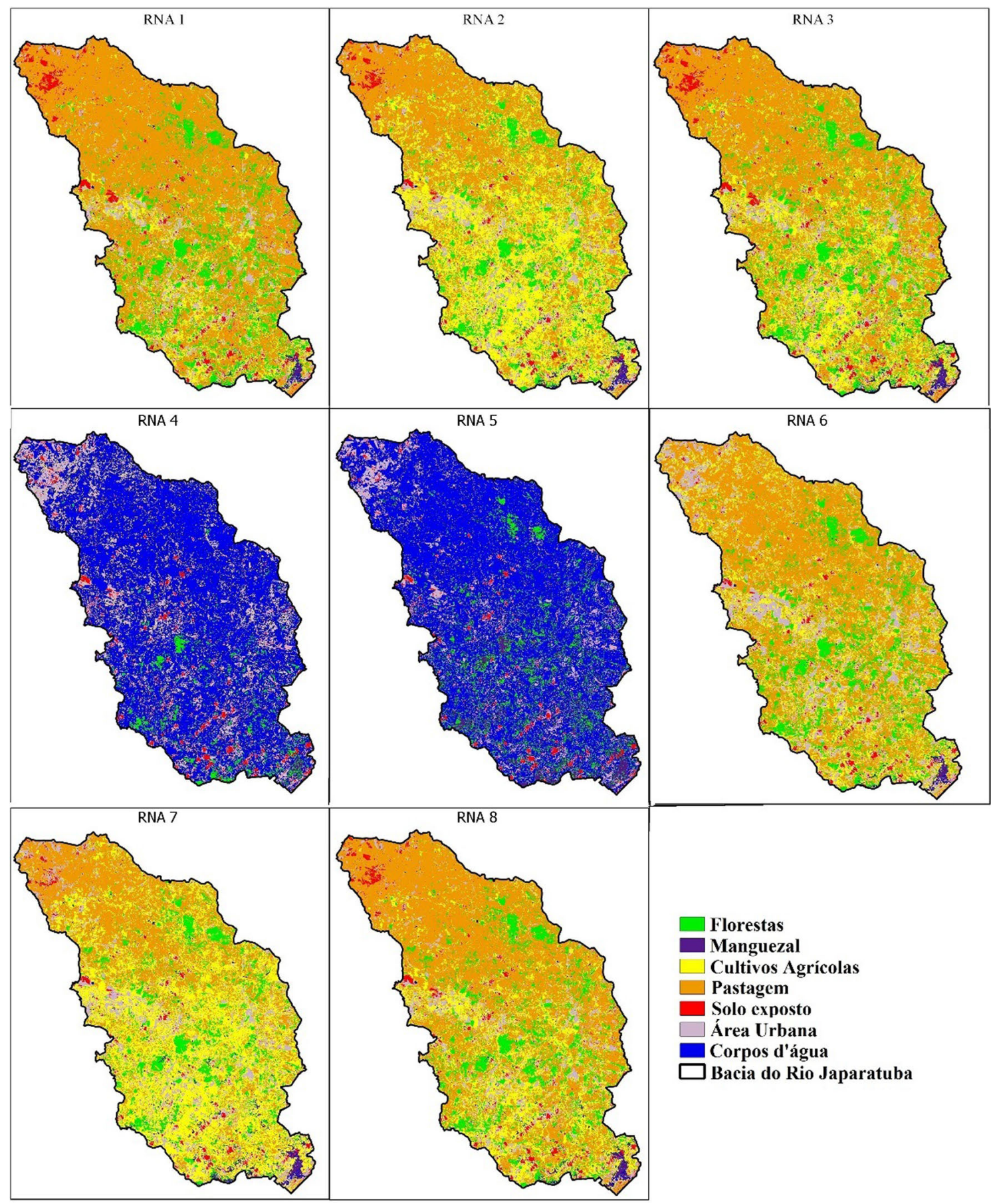

Figura 7 - Classificações de Uso e Ocupação de Solo por RNA.

neurais 4 e 5 geraram produtos em que as classes cultivos agrícolas e pastagem foram completamente negligenciadas em favorecimento da classe corpos d'água, mesmo com uma diferença marcante entre os níveis de cinza apresentados pelas classes suprimidas e a classe corpos d'água.

Ndehedeh et al. (2013), em seu trabalho para avaliarem nove diferente arquitetura de redes neurais backpropagation para a classificação de imagens do satélite
Landsat-7 referentes a cidade de Uyo, Nigéria, também obtiveram resultados destoantes para a RNA com duas camadas ocultas. Apesar de terem encontrado resultados de Exatidão Geral e Índice Kappa elevados e satisfatórios, a RNA com duas camadas ocultas obteve $55 \%$ e 0,46 para os parâmetros supracitados, em que a classificação acabou favorecendo a classe área construída em detrimento das classes florestas e áreas cultivadas. 
Já Zang e Chang (2015) ao compararem redes neurais com duas e três camadas ocultas obtiveram respostas muito semelhantes, com diferença apenas no tempo de processamento para a classificação, a RNA com duas camadas ocultas se mostrou mais lenta do que a RNA com três camadas ocultas.

A Fig. 8 apresenta um gráfico com as áreas em $\mathrm{km}^{2}$ para todas as classes das redes neurais e da classificação por máxima verossimilhança. É possível constatar que tanto para a Máxima Verossimilhança quanto para as três redes neurais com os melhores resultados, respectivamente as RNA 3, 2 e 8, as áreas possuem uma distribuição semelhante. Ou seja, para estes resultados as áreas de pastagem são superiores, seguidas de áreas de cultivos agrícolas e florestas.

No entanto, as redes neurais 3 e 8 apresentaram diferenças entre as classes pastagem e cultivos agrícolas de aproximadamente 450 e $600 \mathrm{~km}^{2}$ cada. Essa diferença não foi constatada nas classificações por máxima verossimilhança e na RNA 2. A presença ou ausência de uma diferença significante entre as duas classes supracitadas se deve à semelhança das características físicas entre as duas classes e por as duas não terem uma fronteira bem definida.

\section{Considerações Finais}

As RNA se mostraram eficientes na classificação de uso de solo a partir de imagens de sensoriamento remoto, tendo em vista que os resultados dos parâmetros de acurácia apresentaram valores que indicam uma concordância quase perfeita na classificação realizada por seis das oito arquiteturas de RNA testadas. Os resultados obtidos pelas RNA foram em média muito próximos aos encontrados pela classificação por Máxima Verossimilhança, método esse já consolidado na literatura e presente em diversos softwares de processamento digital de imagens.

O modelo de RNA usado neste trabalho é bastante simples comparado a outros existentes e pode ser aplicado para resolver problemas complexos de reconhecimento de padrões, modelagem não-linear, e classificação de imagens.

Ficou claro que para o tipo de estudo realizado, uma boa estratégia é fixar os valores dos demais parâmetros e testar arquiteturas em função do número de iterações realizadas na fase de treinamento. O aumento do número de neurônios na camada oculta não se mostrou útil, uma vez que os valores de Exatidão Global e Índice Kappa sofreram reduções consideráveis e o desenvolvimento da REMQ tornou-se muito irregular, apresentando valores mais elevados em relação à RNA com apenas um neurônio na camada oculta.

Os produtos gerados podem ser utilizados como ferramenta técnico-gerencial para a gestão ambiental da área de estudo visto que a BHRJ possui uma dinâmica de uso de solo intensa, apresenta múltiplos usos das águas superficiais, remete importância estratégica socioeconômica e apresenta processos erosivos, assoreamento e contaminação dos recursos hídricos.

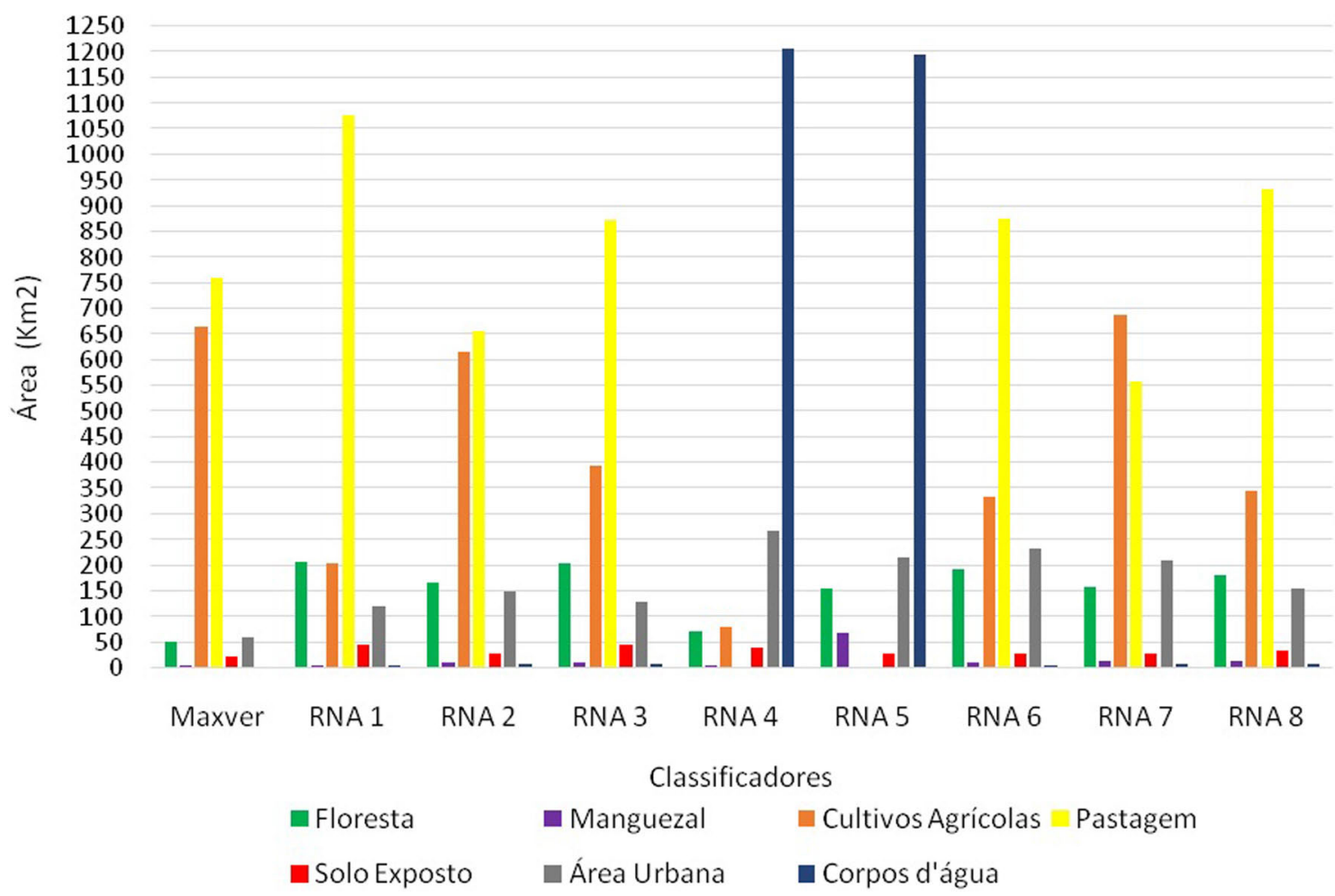

Figura 8 - Áreas das classes para cada classificação realizada. 


\section{Referências}

ANDRADE, A.C.; FRANCISCO, C.N.; ALMEIDA, C.M. Desempenho de classificadores paramétrico e não paramétrico na classificação da fisionomia vegetal. Revista Brasileira de Cartografia, v. 66, n. 2, p. 349-363, 2014.

ARAGÃO, R.; CRUZ, M.A.S.; AMORIM, J.R.A.; MENDONÇA, L.C.; FIGUEIREDO, E.E.; SRINIVASAN, V.S. Modelagem do escoamento na sub-bacia do rio JaparatubaMirim (SE) através do modelo SWAT. Anais XI Simpósio de Recursos Hídricos do Nordeste, 2012.

CASTELLUCCIO, M.; POGGI, G.; SANSONE, C.; VERDOLIVA, L. Land use classification.n Remote Sensing Images by Convolutional Neural Networks, arXiv:1508.00092v1, 2015.

CHAGAS, C.S.; VIEIRA, C.A.O.; FERNANDES, E.I. Utilização de Redes Neurais Artificiais na classificação de níveis de degradação em pastagens. Revista Brasileira de Engenharia Agrícola e Ambiental, v. 113, n. 3, p. 319-327, 2009.

CHEN, Y. ZHAO, X. JIA, X. Spectral-spatial classification of hyperspectral data based on deep belief network. IEEE Journal of Selected Topics in Applied Earth Observations and Remote Sensing, v. 8, n. 6, p. 2381- 2392, 2015.

INGEBRITSEN, S.E.; LYON, R.J.P. Principal components analysis of multitemporal image pairs. International Journal of Remote Sensing, v. 6, n. 5, p. 687-696, 1985.

JENSEN, J.R. Sensoriamento Remoto do Ambiente: Uma Perspectiva em Recursos Terrestres. Parentese Editora: São José dos Campos, 598 p., 2009.

LEÃO, C.; KRUG, L.A.; KAMPEL, M.; FONSECA, L.M.G. Avaliação de métodos de classificação de Imagens TM/ Landsat e CCD/CBERS para o mapeamento do uso e cobertura da terra na região costeira do extremo sul da Bahia. Anais XIII Simpósio Brasileiro de Sensoriamento Remoto, p. 939-946, 2007.

MIDHUN, M.E.; NAIR, S.R.; PRABHAKAR, V.T.N.; KUMAR, S.S. Deep model for classification of hyperspectral image using restricted Boltzmann machine. International Conference on Interdisciplinary Advances in Applied Computing (ICONIAAC), n. 35, p. 1-7, 2014.

NDEHEDEHE, C.; EKPA, A.; SIMEON, O.; NSE, O. Understanding the Neural Network Technique for Classification of Remote Sensing Data Sets. New York Science Journal, v. 6, n. 8, p. 26-33, 2013.

ONUWA, O.; ISONG, M.; EYO, E.; EYOH, A.; NWANEKEZIE, O.; OLAYINKA, D.N.; UDOUDO, D.O.; OFEM, B. GIS Cellular Automata Using Artificial Neural Network for Land Use Change Simulation of Lagos, Nigeria. Journal of Geography and Geology, v. 4, n. 2, p. 94-101. 2012.

OTUKEI, J.R.; BLASCHKE, T. Land cover change assessment using decision trees, support vector machines and maximum likelihood classification algorithms. International Journal of Applied Earth Observation and Geoinformation, v. 12, p. 27-31, 2010.

PENATTI, O.A.B.; NOGUEIRA, K.; SANTOS, J.A. Do deep features generalize from everyday objects to remote sensing and aerial scenes do mains. IEEE Computer Vision and Pattern Recognition Workshops, p. 44-51, 2015.

SEMARH - Secretaria de Estado do Meio Ambiente e Recursos Hídricos. Atlas Digital Sobre Recursos Hídricos, disponível em https://www.semarh.se.gov.br/recursoshidricos/ ?page_id=486, acesso em 14 abr. de 2019, 2016.

SRIVASTAVA, P.K.; HAN, D.; RICO-RAMIREZ, M.A.; BRAY, M.; ISLAM, T. Selection of classification techniques for land use/land cover change investigation. Advances in Space Research, v. 50, n. 9, p. 1250-1265, 2012.

SZUSTER, B.W.; CHEN, Q.; BORGER, M. A comparison of classification techniques to support land cover and land use analysis in tropical coastal zones. Applied Geography, v. 31, p. 525-532, 2011.

WANG, W.; LU, Y. Analysis of the Mean Absolute Error (MAE) and the Root Mean Square Error (RMSE) in Assessing Rounding Model. IOP Conference Series: Materials Science and Engineering, v. 324, 2018.

ZHANG, S.L.; CHANG, T.C. A study of image classification of remote sensing based on back-propagation neural network with extended Delta Bar Delta. Hindawi Publishing Corporation: Mathematical Problems in Engineering, v. 2015, p. 1-10, 2015.

License information: This is an open-access article distributed under the terms of the Creative Commons Attribution License (type CC-BY), which permits unrestricted use, distribution and reproduction in any medium, provided the original article is properly cited. 